\title{
Risk Transfer with CDOs and Systemic Risk in
}

\author{
Banking*
}

Jan Pieter Krahnen, Christian Wilde ${ }^{\dagger}$

June 5, 2006

\footnotetext{
${ }^{*}$ We are grateful for financial support by Deutsche Forschungsgemeinschaft (DFG) and by Frankfurt University's Center for Financial Studies (CFS). This paper is part of CFS' project on the Economics of Credit Risk Transfer. In developing the basic question of this paper, we owe a lot to mini workshops with Günter Franke as well as Dennis Hänsel and Thomas Weber. Furthermore, we thank Falko Fecht and Ian Marsh for helpful comments. We also thank seminar participants at the 2005 Meeting of the German Finance Association in Augsburg, the 2005 Annual meeting of the Verein für Socialpolitik in Bonn, the 2005 Workshop on Credit Risk Management in Obergurgl, Max Planck Institut in Bonn, WHU Koblenz, and the annual conference of CERF in Cambridge.

$\dagger^{\dagger}$ Finance department, Goethe-University, Frankfurt. Correspondence: Christian Wilde, Mertonstr. 17-21 (PF 88), D-60054 Frankfurt(Main), Germany, E-Mail: krahnen@wiwi.uni-frankfurt.de, wilde@finance.uni-frankfurt.de.
} 


\begin{abstract}
Large banks often sell part of their loan portfolio in the form of collateralized debt obligations (CDO) to investors. In this paper we raise the question whether credit asset securitization affects the cyclicality (or commonality) of bank equity values. The commonality of bank equity values reflects a major component of systemic risks in the banking market, caused by correlated defaults of loans in the banks' loan books.

Our simulations take into account the major stylized fact of CDO transactions, the non-proportional nature of risk sharing that goes along with tranching. We provide a theoretical framework for the risk transfer through securitization that builds on a macro risk factor and an idiosyncratic risk factor, allowing an identification of the types of risk that the individual tranche holders bear. This allows conclusions about the risk positions of issuing banks after risk transfer.

Building on the strict subordination of tranches, we first evaluate the correlation properties both within and across risk classes. We then determine the effect of securitization on the systematic risk of all tranches, and derive its effect on the issuing bank's equity beta. The simulation results show that under plausible assumptions concerning bank reinvestment behavior and capital structure choice, the issuing intermediary's systematic risk tends to rise. We discuss the implications of our findings for financial stability supervision.
\end{abstract}

JEL classification: G28

Keywords: risk transfer, systematic risk, systemic risk 


\section{Introduction}

Securitization of loan assets has become a common instrument of bank risk management. According to ECB (2004), a survey published by the European Central Bank in 2004, about 8-15\% of overall assets of large, international banks, have been subject to a securitization transaction. Many observers, such as J.P. Morgan (2004), believe the market for asset backed securities (ABS) to grow rapidly in the next couple of years. What is the impact of securitizations on the risk exposure of the issuing institutions? In particular, how are commercial banks affected that hold large volumes of loans on their balance sheets and that engage in securitizing them?

The answers to these questions are not obvious at all. According to Greenbaum and Thakor (1987), credit securitization allows a bank to reduce its risk exposure, and to increase diversification in the economy. In the model of Duffie and Gârleanu (2001), securitizations improve liquidity and induce a positive overall market value effect. However, the effective risk transfer from a bank's balance sheet is limited by moral hazard problems. Allen and Gale (2004) argue that, for incomplete markets, credit risk transfer may in fact increase risk concentration rather than risk diversification, thereby raising overall systemic risk. While risk transfer has often been cited as a major driver of ABS market development, we will show below that in a typical CLO and CDO transaction (i.e. collateralized loan obligations, collateralized debt obligations), risk transfer is rather limited, irrespective of the impressive size of the issues. The key to understanding risk transfer in structured transactions, such as ABS and CDOs, 
lies in the non-proportional sharing of risk. The tranching of claims, and the application of the subordination principle, lead to a reshuffling of risk in the portfolio. Typically, tail risk is being transfered, while non-tail risk is retained by the issuing bank. This is particularly true for asset pools that are subject to moral hazard, such that retention of the most junior tranche, the first loss piece, serves as a bonding and signaling device (DeMarzo, 2005). Tranching and securitization therefore alters, or may alter, three aspects of the issuer's risk position. First, it truncates the loss rate distribution. Second, it affects the correlation between on-balance sheet assets and, third, it may change the systematic risk of the company, its exposure against market-wide risk factors.

In this paper we address all three consequences of asset securitization. We model a bank that repeatedly securitizes its loan portfolio, while retaining the first loss piece, and that reinvests the proceeds by lending to customers. Given the risk characteristics of the loan portfolio, how does securitization change the basic properties of the bank's remaining loan book, i.e. its loss rate distribution? what are the correlations between the retained asset portions and the remaining asset on the balance sheet? Furthermore, how can the risks be characterized that are transfered off the balance sheet, and on to the buyers' books? Are they mostly systematic or rather company-specific, i.e. of an unsystematic nature? Finally, how is the dependence of bank equity values on a macroeconomic factor affected, does it increase or decrease?

Our analysis is of major importance for investors and for regulators. In line with Das et al. (2004), investors will price structured finance products, like 
senior or mezzanine tranches of a CDO transaction, by looking at the amount of systematic default risk that they carry. For this purpose, systematic default risk has to be estimated. For regulators, risk shifting between banks and capital markets is relevant since it may affect the required capital base of individual banks and, even more importantly, it may affect the exposure of the banking system at large vis-à-vis macroeconomic risks, see Andersen et al. (2004).

The analysis relies on a two-stage procedure: First, the loss distribution of the underlying portfolio has to be determined. Subsequently, the loss distribution is allocated to tranches, representing claims of different seniority on the underlying portfolio. We apply a Monte Carlo simulation to model the loss distributions for portfolios of bank loans. For tranching, we apply cut-off values represented by maximum default probabilities allowed for each tranche. In practice, these values are indicated by rating agencies. The data are then used to describe the correlation property between tranches of different seniority and/or different underlying asset pools. Our asset value model allows to disentangle the effects of an economy-wide risk factor from risks associated with an industry, or a particular company.

The results show that, among tranches of different transactions with the same credit quality (intra-rating correlations), the most senior tranches have the highest correlation coefficient.

Second, the sensitivity of tranches to realizations of the macro factor is related to the degree of subordination. In particular, senior tranches have a low systematic risk, while junior tranches show high systematic risk. 
These findings allow to asses the effect of securitizations on the systematic risk of bank equity and, ultimately, on the systemic risk of the banking industry as a whole. We argue that, as the banks apply themselves to the securitization of individual loan books, they will most likely increase their systemic exposure, rather than reduce it. This, in turn, will contribute to an increase in the probability of banking crises.

The paper is structured as follows: First, we describe how CDOs can be modeled. We present the model setup, based on a firm-value model, and discuss the implementation based on Monte Carlo simulation. Second, we look at a single transaction and investigate which risks are transfered from the underlying loan portfolio to tranches as part of securitization. Third, we turn to the level of individual institutions. We infer the consequences of securitization for the risk positions of typical banks and examine the benefits of loan portfolio diversification in the context of securitization. We also derive how bank equity betas change after banks securitize their loan portfolios. Fourth, at the level of the overall economy, we examine the interaction of banks and the consequences of securitization for systemic risk. In the concluding section we discuss the implications of our findings for financial stability supervision and risk management. 


\section{Modeling CDOs}

In this section we will analyze the risk charactristics of asset backed securities and related financial instruments ${ }^{1}$. We construct a simple tool that allows us to portray the loss distribution of asset portfolios, and of any tranche that is derived from the same underlying portfolio.

\subsection{Model setup}

We apply a firm-value model to capture the occurrence of obligor default. More precisely, we apply a structural one-factor correlated default model. The driving factor is a market factor, and company value is modeled as the interplay of the market factor and a company specific, idiosyncratic risk factor. This market model approach is the model of choice in most corporate finance applications. We model company value $V_{n, t}$ of each obligor $n \in\{1,2, \ldots, N\}$ at any time $t$ before maturity as being driven by a generalized macroeconomic factor $Y_{t}^{M}$ that is common to all securities, and an idiosyncratic component $\epsilon_{n, t}$ :

$$
V_{n, t}=\sqrt{\rho_{n}^{M}} Y_{t}^{M}+\sqrt{1-\rho_{n}^{M}} \epsilon_{n, t}
$$

with $Y_{t}^{M} \sim \Phi(0,1)$, and $\epsilon_{n, t} \sim \Phi(0,1)$. Thereby, we obtain correlated asset values of obligors. In case the sensitivities $\sqrt{\rho_{n}^{M}}$ of firm values to the macroeconomic risk factor are the same for all obligors $n$, then $\rho_{n}^{M}$ corresponds to the

\footnotetext{
${ }^{1}$ Asset backed securities are structured financial instruments that share two basic features: the pooling of underlying financial claims, and their tranching into a set of bonds, differentiated by the degree of subordination. See Jorion or Fabozzi for institutional details.
} 
mutual correlation coefficient for all assets. ${ }^{2}$ The chosen one-factor approach is often the model choice in previous studies, such as Gibson (2004), among others.

Obligor $n$ is assumed to default if at any time $t$ the value $V_{n, t}$ of its assets lies below the exogenously given default boundary $D_{n}$, i.e. $V_{n, t}<D_{n}$. $V_{n, t}$ is assumed to be normally distributed and is standardized such that $V_{n, t} \sim \Phi(0,1)$.

There is a simple relation linking every default boundary $D_{n}$ to a particular default probability $p_{n}$ :

$$
D_{n}=\Phi^{-1}\left(p_{n}\right)
$$

Usually, a fraction of the notional amount can be recovered in case of default. Let $\psi_{n}$ denote the recovery rate and $\theta_{n}$ the exposure size of security $n$. Portfolio loss is given as the sum of individual loan losses. We define the portfolio default rate $P D R$ as the present value of portfolio loss divided by the net present value of all promised payments until maturity:

\footnotetext{
${ }^{2} \mathrm{~A}$ more general model setup allowing for both inter- and intra-industry correlation could include, besides the market factor, orthogonal industry factors $Y_{t}^{j}$ for industries $j \in\{1,2, \ldots, J\}$. The company value of each obligor in industry $j$ can be modeled as: $V_{n, t}^{j}=\sqrt{\rho_{n}^{M}} Y_{t}^{M}+\sqrt{\rho_{n}^{j}} Y_{t}^{j}+\sqrt{1-\rho_{n}^{M}-\rho_{n}^{j}} \epsilon_{n, t}$, with $Y_{t}^{M} \sim \Phi(0,1), Y_{t}^{j} \sim \Phi(0,1)$, and $\epsilon_{n}^{t} \sim \Phi(0,1)$. We assume that securities within industries are driven by a factor $Y_{t}^{j}$ that is orthogonal to $Y_{t}^{M}$ and specific for that particular industry, i.e. $\operatorname{Cov}\left(Y_{t}^{i}, Y_{t}^{j}\right)=0$ for $i \neq j$. Thereby, we obtain correlated asset values of obligors within the same industry, with correlation coefficient $\rho_{n}^{j}$ for industry $j$. The chosen representation also allows for inter-industry correlations, captured by $\rho_{n}^{M}$. This approach is quite general and accounts both for both inter- and intra-industry correlations. Its structure encompasses the approaches commonly applied by major rating agencies, which rely on a one factor model for each industry and zero inter-industry correlation. Thus, it reduces to the classical market model if industry-specific risk is zero, while it reduces to the agency model if only the industry-specific component has explanatory power.
} 


$$
P D R=\frac{\sum_{n=1}^{N} 1_{\left\{T_{n}>\tau_{n}\right\}} \cdot \theta_{n} \cdot\left(F_{n} \cdot\left(1-\psi_{n}\right) \cdot e^{-r \tau_{n}}+C_{n, \tau_{n}, T_{n}} \cdot e^{-r T_{n}}\right)}{\sum_{n=1}^{N} \theta_{n} \cdot\left(F_{n}+C_{n, 0, T_{n}}\right) \cdot e^{-r T_{n}}},
$$

where $1_{\left\{T_{n}>\tau_{n}\right\}}$ is an indicator function taking the value one if security $n$ defaults during its lifetime and zero otherwise. $T_{n}$ represents maturity of security $n$, and $\tau_{n}$ is the time of default. $F_{n}$ denotes the redemption value and $C_{n, s_{n}, t_{n}}$ represents the present value at time $t_{n}$ of all coupon payments for security $n$ paid in the time interval $\left[s_{n}, t_{n}\right]$. All payoffs are discounted with interest rate $r$.

The applied firm value model as presented in Eq. (1) is suitable for a simulation exercise.

\subsection{Model implementation}

In the implementation, we do not need to apply simplifying assumptions to determine the loss distribution of the underlying portfolio. Instead, we are able to fully profit from the Monte Carlo Simulation procedure. Analytical approaches often rely on limiting assumptions, e.g. that the portfolio is composed of an infinite number of securities with identical characteristics. Thus, analytical models to some extent may be suitable for sensitivity analyses, but Monte Carlo Simulation is more appropriate for real-world applications. All individual securities in the portfolio can be accounted for by their specific exposure size, recovery rate, default probability, and maturity. Furthermore, Monte Carlo Simulation 
allows to differentiate between obligors and individual securities. The occurrence of joint obligor defaults is modeled by accounting for the sensitivity of each individual obligor to the common factor.

The loss distribution is simulated in 5 steps: First, a realization of the macro factor is simulated until maturity. Subsequently, default scenarios are generated for all individual obligors in the portfolio. Default occurs, if the simulated firm value of an obligor, based on realizations of the macro factor and an idiosyncratic term, falls below the default boundary. The default boundaries correspond to cut-off values denoting the maximum default probability allowed for a tranche of a particular seniority. In the third step, individual loan losses are obtained by applying a recovery rate to loan default. Fourth, portfolio loss is given as the sum of realized individual loan losses. This corresponds to one realization in the simulation. Fifth, many simulation runs yield the loss distribution of the entire portfolio.

The loss distribution depends on various input factors that may be grouped into three categories: Individual loan components, portfolio components, and additional CDO features. Individual loan components comprise maturity, credit quality, and credit migration probability, and expected recovery rate at default. Portfolio components comprise the sensitivities of the individual loans to the common factor, portfolio diversification, and individual obligor concentration. Furthermore, in practice, CDO loan portfolios present additional complications as they are dynamic portfolios with various restrictions concerning asset replenishment over the lifetime of the issue. The implementation applied in this paper 
accounts for single issuer default as well as portfolio characteristics, which are the focus of the investigation.

\section{Risk allocation to tranches}

\subsection{Individual tranche characteristics}

We now investigate the nature of risk transfer from the underlying portfolio to tranches. This is at the heart of structured finance products, pooling of individual risks in order to reallocate these risks to investors. The transfer of risks is non-proportional, or non-linear, due to the principle of subodination of tranches. To estimate the resulting risk allocation we rely on a Monte Carlo simulation. Let us consider a reference portfolio with 10'000 loans. All securities have the same characteristics: identical exposure size, $6 \%$ coupon, 1 year to maturity, $20 \%$ default probability, $47.5 \%$ recovery rate, and identical exposure to the macro factor, corresponding to a correlation of $\rho_{n}^{M}=0.3$ between all securities. All cash flows are discounted with a constant interest rate of $4 \%$. The evolution of individual-loan credit quality over time is simulated at annual frequency. Figure 1 shows the loss distribution obtained by Monte Carlo Simulation with 50'000 simulation runs. The loss distribution has a typical shape for portfolios subject to credit risk, as it has a substantial positive skewness. The sensitivity of the individual loans to the macro factor is an important input parameter determining the shape of the distribution. The higher it is, the more probability mass is shifted from the middle to the tails of the distribution and 
vice versa.

Subsequently, the portfolio is split into seven tranches of strict subordination. Note that all results reported below remain essentially unchanged if the number of tranches is changed to, say 5 or to 9 tranches. In practice, the tranches are associated with different ratings by rating agencies. For given maturities of the tranches, the ratings in turn correspond to specific default probabilities. We define the tranches by a maximum default probability, which is fixed at the $1 \%, 2 \%, 5 \%, 10 \%, 20 \%$, and $30 \%$ quantile of the loss rate distribution. Threshold probabilities are round numbers for convenience only. We number the tranches from 1 to 7 , with the seventh tranche being the first loss piece, or equity piece, which covers the residual loss. Tranche no.1, at the other end of the spectrum, refers to the most senior tranche. All remaining tranches, nos. 2-6, are mezzanine tranches.

Tranching is done with the intention of minimizing the size of the first loss piece, given the number of different layers and their respective threshold values. Applying the loss distribution of the total portfolio leads to the following tranche sizes starting from the most senior tranche: $0.6161,0.0370,0.0554,0.0514$, $0.0602,0.0393$, and 0.1406 for the equity piece. Further summary statistics for the tranches are provided in Table 1. Graphical representations of the loss distributions for different tranches (senior tranche, mezzanine tranche, and first loss piece) are given in Figure 2.

In Table 1, the senior tranche is by far the largest part of the entire transaction, making up $61.61 \%$ of the transaction. The expected loss rate is only 7 
basis points, while expected loss given a default event is 668 basis points. The mean loss rate is monotonic increasing in the degree of subordination. Its maximum value is $60.96 \%$ for the equity piece. The default probability of the equity piece is almost $100 \%$, as there were only 2 out of 50 '000 runs in the simulation that came out with a zero loss rate for the entire portfolio. The numbers for the senior tranche are particularly striking, as they show a very low loss given default rate, despite its large size. Figure 2 explains why this is the case. Realized portfolio losses that surpass the capacities of the more subordinate tranches cluster at the low end of possible loss rates, without any observation exceeding a $25 \%$ loss rate in the simulation runs. Clearly, the distribution of losses in this tranche is sensitive to the extreme-value properties of the underlying risk factors ${ }^{3}$.

As can be seen from Figure 2, the most subordinate mezzanine tranche, no. 6, displays a broad tendency of a downward sloping distribution function throughout its domain. While the loss rate distributions for all mezzanine tranches are downward sloping, their slope decreases with the degree of seniority of the tranche in question for standard portfolio loss distributions and standard cut-off values for tranches.

The distribution of the first loss piece, depicted in Figure 2, is single peaked in the interior of its domain, abstracting from the spike at its upper boundary. This follows from the fact that the lowest tranche comprises two thirds of the cumulative loss rate distribution, comprising the peak of the aggregate loss rate

\footnotetext{
${ }^{3}$ This points at a natural extension of our analysis, which uses fat-tailed distributions to model the loss rate distribution of the underlying loan portfolio.
} 
distribution.

From the simulation exercise we obtain a couple of insights. By tranching, the risks of the underlying portfolio are allocated in a non-proportional way to the tranches. The loan portfolio is transformed into several securities with entirely different risk characteristics. The tranches or only a selection of them, as is often intended, can subsequently be sold independently to investors. The senior tranche has the highest quality in all categories. The probability of default is lowest, with no loss in $99 \%$ of all cases in this example. In addition, mean loss, loss standard deviation, and loss given default are lowest among all tranches. Furthermore, the senior tranche is by far the largest of all tranches, with a claim on $61.61 \%$ of the volume of the underlying portfolio. In contrast to the senior tranche, the first loss piece suffers a loss rate of $100 \%$ with a large probability of 30\%. Furthermore, while low losses occur at low frequency, higher losses occur with an increasing likelihood, peaking at a loss of $22 \%$. Overall, the FLP has the highest expected loss of all tranches. Finally, the presented statistics illustrate that even reference portfolios of relatively bad quality (20\% default probability over 1 year for all loans in this case) can be divided into one large tranche of the highest quality, a couple of mezzanine tranches, and a relatively small first loss piece in which the major proportion of credit risk is concentrated.

\subsection{Tranche interdependencies}

In this section, we use the data generated in the simulation exercise in order to investigate the correlation between tranches. Since the underlying structural 
model differentiates between macoeconomic and idiosyncratic risk, we will now use the risk model presented in the pevious section in order to identify the exposure of single tranches to the macroeconomic risk factor. The analysis shows that non-proportional risk sharing allocates macro risk primarily to junior tranches. The correlation between tranches of different issues is analyzed, e.g. the correlation between two first loss pieces, or two senior tranches with distinct underlying asset portfolios. Since we control the data generating process, we can trace the effect of changes in the underlying asset correlations to the resulting tranche correlations.

Table 2 displays the bilateral correlations of all tranches (ranging from senior tranche to the first loss piece) from two different CDOs with identical characteristics. Note that for large portfolios, the correlation pattern converges in the limit to that of same-issue tranches. The results indicate that tranches of similar credit quality, or seniority, have higher correlation values than tranches with different credit quality. The correlation between tranches decreases monotonically with increasing distance of quality of two tranches. The highest correlation values are obtained for tranches with the same credit quality. These values are close to one. Correspondingly, the lowest bilateral correlation value (0.0906) is obtained for tranche 1, the most senior tranche, and tranche 7 , the most junior tranche. This shows that senior tranches are almost orthogonal to junior tranches, in particular to the equity piece. Note that even lower correlations can be attained by increasing the distance of tranches, e.g. by decreasing the maximum default probability allowed for the senior tranche. 
To determine the robustness of the obtained correlation pattern, the input parameters of the presented base case are altered. Table 3 displays the bilateral tranche correlations of two different CDOs where the correlation between individual obligors in the reference portfolios is decreased to 0.15 . Both the individual correlations and the correlation pattern is very similar to that of Table 2 .

In an additional robustness check, the number of individual securities in the reference portfolio is altered. In particular, the reference portfolio is assumed to consist of 100 loans from different obligors, and the correlation between them is 0.3 as in the base case. The results are presented in Table 4. Again, both the individual correlations and correlation pattern is very similar to that of the base case in Table 2 .

In both robustness checks, the influence of the macro factor is reduced while the influence of idiosyncratic components increase. However, a comparison of Tables 2 to 4 reveals that the change in tranche correlation depends on the type of variation. While correlations of tranches of similar seniority change more when obligor correlations are reduced to 0.15 , correlations of tranches with different credit quality react more to changes in the number of securities in the reference portfolio.

According to these simulations, the results confirm that portfolio risk is transferred to tranches in a non-linear way. In particular, the risk associated with senior tranches is only to a minor extent correlated with the risk that remains on the bank's balance sheet, given the retention of the first loss piece. 
This raises the question to what extent this result depends on the diversification among the assets in the underlying loan portfolio. We turn to this question next.

\subsection{Estimating the systematic risk of tranches}

The objective of the analysis is to trace the effect of macroeconomic risk to the risk exposure of individual tranches, structured according to the principle of subordination. This section has an important result: under quite general assumptions about tranching, the most subordinate tranche has the largest macrofactor dependency. Tranching therefore tends to increase an issuers systematic equity risk, provided the most junior tranche is retained, a wide-spread industry practice. To capture the impact of systematic risk on tranches, we consider a bond that only depends on the macroeconomic factor and does not exhibit any idiosyncratic risk. This bond, which we call a macro bond, is assumed to have otherwise identical characteristics to the bonds in the portfolio, i.e. 1 year to maturity, $6 \%$ coupon, $20 \%$ default rate, and $47.5 \%$ recovery rate. The macro bond allows us to estimate directly the relationship between the macro risk factor and the realizations of particular tranches of an underlying loan portfolio. In our setting of normally distributed realizations, the default rate of $20 \%$ corresponds to a default boundary of -0.8416 according to the distribution function of (macro bond) value realizations $V_{n, t}$ in Eq. (1), where $\rho_{n}^{M}$ is set equal to one. Table $\mathbf{5}$ summarizes the results, comparing joint default events of the tranches and the macro bond. The second column reports the unconditional default rates of the tranches, as specified for the simulation in this paper. The third column 
reports the default rate of the tranche conditional on the default of the macro bond. This conditional tranche default rate is monotonic in the tranche quality, leading to the highest value of $100 \%$ for the most junior tranche, and to $4.95 \%$ for the most senior tranche. Note that these conditional default probailities are almost four times higher than the unconditional probabilities for tranches 1 to 5.

The fourth column specifies the conditional macro bond default rate, i.e. the probability of a macro bond default, given the default of a particular tranche. This conditional default rate is $100 \%$ for all senior tranches, and gradually decreases for junior tranches. For the first loss piece, the conditional default rate is lowest, with a value of $20.15 \%$ in our simulation.

The results in Table $\mathbf{5}$ show that the impact of macro risk on the default rates of tranches varies systematically with the rating quality of the tranche. According to the last column, the more senior a tranche is, the more likely is its default accompanied by a negative realization of the macro risk factor.

Figure 3 relates tranche losses to realizations of the macro factor. The first loss piece suffers losses even for very good realizations of the macro factor. The capacity of the first loss piece is exhausted already for macro factor realizations around the 30 percent quantile. For lower realizations, the losses of the first loss piece are truncated at its share of the reference portfolio, corresponding to a loss of 100 percent. In constrast to the first loss piece, the senior tranche only suffers losses in the case of extremely bad realizations of the macro factor. Note that the senior tranche even in the worst case only suffers minor losses although 
it has by far the largest size of all tranches. This is due to the recovery that truncates losses of the senior tranche.

We now turn to the estimation of a central measure of tranche interdependency on a market, which is beta, the systematic risk of individual tranches. This measure of risk is used in portfolio theory to capture the degree of procyclicality of two random variables. A beta value larger (smaller) than one characterizes a return series that exhibits more (less) cyclical variation then the benchmark index. In calculating tranche betas we take the macro factor $Y_{M}^{t}$ as the benchmark index. Table 6 shows the sensitivity of the individual tranches to the macro risk factor. In particular, the realized tranche returns obtained in the simulation runs are regressed on the macro risk factor. Besides the base case, two alternative scenarios are reported where the number of loans and the correlation are varied, respectively. The estimated betas increase with the level of subordination, indicating that the first loss piece has a high sensitivity to the macro risk factor while the most senior tranche almost has none. However, this relation is not monotonic since in some cases, the sensitivity of the first loss piece to the macro risk factor is slightly lower than that of the next senior tranche. Nevertheless, in all reported cases, the sensitivity of the first loss piece to the macro risk factor is higher than that of the total reference portfolio. ${ }^{4}$ Thus, with tranches being exposed to different degrees of systematic risk, also the exposure of the issuing institution to systematic risk changes in the practically relevant case that not all tranches are sold.

\footnotetext{
${ }^{4}$ This result is confirmed in additional simulations with alternative parameter settings.
} 


\section{Implications for Bank Risk}

In this section, we investigate the risk position of a bank that issues a CDO, assuming that it retains the first loss piece, the most junior tranche. We make this assumption since it is believed to be common practice among international banks. We have no direct evidence supporting this assumption and therefore refer to survey results (See ECB 2004 and Bundesbank 2004). This section shows that under fairly general assumptions concerning bank reinvestment behavior, risk transfer will simultaneously decrease its exposure vis-à-vis extreme risks and increase its overall macro-factor dependence. We therefore predict issuing banks to increase their equity beta.

\subsection{Securitization and reinvestment}

We now investigate the risk position of a bank that issues CDOs. Typically, a bank is exposed to various types of risk, in particular market risk, credit risk, and operational risk. Market risk is often defined as outcomes from position taking (stock, interest-sensitive securities, foreign exchange) as well as customer-related activities (fees and provision). Credit risk incurs from lending which generates fees and interest income. Finally, operational risk as defined by the Basle Committee are losses due to external events and failure of internal processes, people, or systems. The distributions of all mentioned sources of risk have distinct characteristics. Market risk is typically assumed to have a symmetric distribution with a high variance, operational risk is typically assumed to have a very thin distribution with large tails, and credit risk is assumed to 
have a skewed distribution with limited gains, but unlimited loss potential. On average, the banks' exposure to credit risk is about 6.5 times higher than to market risk, as obtained by [19], and thus the distribution of credit risk has a dominating impact on the overall risk distribution of a bank. What is the resulting risk position of a bank that actively securitizes its loan portfolio?

The impact of securitization on overall bank risk crucially depends on how the proceeds are reinvested. The resulting effect is not obvious as there is a whole range of possiblilties. In the extreme case on the one side, the balance sheet of the bank risk is levered, either by distributing the proceeds to shareholders or by entering new investments with similar risk characteristics as the retained junior tranche. In the other extreme, overall bank risk also can decrease with a securitization transaction. This is the case when the proceeds are invested in new projects with lower risk. Thus, depending on the new risk position following securitization and re-investment, a bank will have to hold more or less equity according the capital accords of the Basle committee. Seen from a dynamic perspective, the bank will either be exposed more or less to the fluctuations of the overall economy. Thus, while the Basle 2 accords have pro-cyclical effects, securitization (and re-investment) allows to influence a bank's risk sensitivity to the overall economy and thereby the capital requirements. Thus, securitization allows banks to pursue its lending business independently of the state of the economy, in spite of cyclical effects imposed by the Basle 2 regulation.

To determine the resulting risk position of a bank that actively securitizes its loan portfolio, we investigate the special case of a bank that repeatedly 
securitizes its loan portfolio and reinvests the proceeds. It turns out that a bank that repeatedly securitizes its loan portfolio and reinvests the proceeds will have an entirely different risk position after these transactions. With each iteration, the bank increases its leverage. Figure 4 shows the credit risk exposure of a bank that repeatedly securitizes its loan portfolio, retains the first loss piece and reinvests the proceeds in loans of the same quality characteristics in terms of loss distribution. We start out from a simulated loss distribution obtained for a benchmark portfolio with 10'000 individual loans and 1 year to maturity. The default probability of the loans in the portfolio is $20 \%$, and the recovery rate in case of default is $47.5 \%$. Applying the Monte Carlo Simulation technique to this portfolio leads to the distribution of the original portfolio. The obtained average loss rate is $11.07 \%$ with a standard deviation of $8.93 \%$.

After every round of securitizing and reinvesting, the resulting relative loss distribution of the bank changes with the number of iterations and takes a distinct shape, differing from that traditionally assumed for credit risk exposures. This has important implications for firm-wide risk management of the bank. Repeated securitization and reinvestment uniformly increases the return variance of the securitizing bank and the value-at-risk. The special case of identical loss rate distribution for the initial loan portfolio and all new (reinvested) loan portfolios has a simple limit result: the loss distribution of the portfolio with repeated reinvestment converges to that of the original first loss piece. However, even a small number of iterations transforms the bank's loss rate distribution substantially, reducing its skewness and increasing its mean value. Already after 
one round, mean loss rate and standard deviation increase substantially and take the values $18.09 \%$ and $12.07 \%$, respectively. The limit distribution has a mean loss rate of $60.96 \%$ and a standard deviation of $34.28 \%$, while the probability of a complete asset loss is $30 \%$ (compared to $0.00 \%$ in the original portfolio). This latter number is also the probability that the bank goes bankrupt provided that it is completely equity financed and has no additional income from sources other than lending. The results are important for bank risk management and regulation likewise.

\subsection{Estimating the effect of granularity}

In this section, we investigate the effect of increasing granularity on the standard deviation of the asset portfolio. We will trace the effect of diversification on the average correlation by varying the number of assets (loans) in the underlying pool. We carry out this basic test, because we are interested in the effect of securitization on diversification. One hypothesis advanced in the literature is that a bank that engages in the transfer of risk through tranching increases the diversification in its asset base. The reason is that the proceeds from a securitization can be reinvested in new loans, thereby increasing the granularity of the loan book.

We consider a reference portfolio with a varying number of loans. All loans have a default probability of $20 \%, 1$ year to maturity, $47.5 \%$ recovery rate, and $6 \%$ coupon. Table 7 presents the standard deviation of losses after accounting for the number of loans. All loans are assumed to have a default correlation 
of 0.0 and 0.3 , respectively. The calculations for the different portfolios are performed with 50'000 simulation runs each.

The results suggest that even a small number of loans in a portfolio is enough to diversify away the major part of idiosyncratic default risk. Consider the first column. The asset base is assumed to consist of uncorrelated risks, and the idiosyncratic risk (standard deviation) is $22.13 \%$. If the number of loans increases, the standard deviation of the portfolio loss rates is rapidly decreasing, approaching zero. For example, with an asset base of 1000 loans, the resulting portfolio standard deviation is reduced by $1-\frac{0.7}{22.13}=96.84$ percent, relative to the original level, the standard deviation of the loss rate distribution of a single loan. As can be seen from columns 2 and 3, the decrease in standard deviation is a function of the bi-variate correlation between assets. For instance, if the correlation is 0.3 , an asset base of 1000 loans reduces portfolio standard deviation to $8.98 \%$ of its original level. This number, however, is numerically close to portfolio standard deviation that can be reached when the asset base is decreased by a factor of 10 . In this case, the resulting standard deviation is $9.19 \%$, i.e. increases the standard deviation by a factor of $1.023(+2.3 \%)$. Put differently, increasing the granularity of a portfolio has only a minor effect on portfolio standard deviation, provided the number of loans in the initial portfolio exceeds 100. This exponential phasing out of the granularity effect happens earlier (i.e. with a small number of loans in the initial portfolio) if the bi-variate loan correlation is high. For lower correlations, the phasing out happens at higher degrees of granularity, but the overall effect is already close 
to complete with merely 100 assets. The exception is a bi-variate correlation of 0.0, where the reduction of standard deviation for each increase of the number of loans by the factor 10, can be approximated by a constant factor, 3.1 in our simulations.

Overall, the results demonstrate that the diversification benefits are rapidly decreasing with the number of securities in the portfolio. Typically, banks hold very large loan portfolios and the securitization of a bank's loan book will only marginally increase asset granularity. Thus, contrary to what is often believed, securitizing a bank loan portfolio with subsequent reinvestment in new loans will only have minor additional diversification benefits for banks.

\subsection{Implications for bank beta}

We now examine the effect of securitization on the exposure of banks to systematic risk. In particular, how does bank equity beta change in connection with a securitization transaction? For simplicity, we assume that a bank is only pursuing a lending business and that it has no other assets than its loan portfolio. On the other hand, the liabilities comprise equity and debt. We now examine how a bank's beta changes with securitization, assuming that the bank securitizes its entire loan portfolio.

In line with the results obtained in Table $\mathbf{6}$, we assume that the beta of a tranche is related to its seniority and in particular, that the following inequality holds: 


$$
\beta_{F L P}>\beta_{P F}^{\text {orig }}=\beta_{\text {assets }}^{\text {orig }}
$$

where $\beta_{F L P}$ is the beta of the first loss piece and $\beta_{P F}^{\text {orig }}$ is the beta of the original reference portfolio.

Generally, a bank's asset- and equity-beta can be related by the following equation:

$$
\beta_{\text {assets }}=\beta_{\text {debt }} \cdot d+\beta_{\text {equity }} \cdot e,
$$

where $\beta_{\text {assets }}, \beta_{\text {debt }}$, and $\beta_{\text {equity }}$ are the betas of the assets, debt, and equity, respectively. The debt ratio is denoted by $d$, and the equity ratio is denoted by $e$.

The relation between original and new bank equity beta can be expressed in a general way by using Eq. (4):

$$
\begin{aligned}
\Delta \beta_{\text {equity }} & =\beta_{\text {equity }}^{\text {new }}-\beta_{\text {equity }}^{\text {orig }} \\
& =\frac{\beta_{\text {assets }}^{\text {new }}}{e^{\text {new }}}-\frac{\beta_{\text {assets }}^{\text {orig }}}{e^{\text {orig }}}-\frac{\beta_{\text {debt }}^{\text {new }} \cdot d^{\text {new }}}{e^{\text {new }}}+\frac{\beta_{\text {debt }}^{\text {orig }} \cdot d^{\text {orig }}}{e^{\text {orig }}}
\end{aligned}
$$

where $e^{\text {orig }}\left(d^{\text {orig }}\right)$ is the original and $e^{\text {new }}\left(d^{\text {new }}\right)$ is the new equity (debt) ratio after securitization.

The new asset beta $\beta_{\text {assets }}^{\text {new }}$ depends on how the securitization proceeds are reinvested, i.e. which sensitivities the new securities have to the macroeconomic 
risk factor. Let $s$ denote the securitization proceeds in percent of the original portfolio. Correspondingly, the percentage of the retained first loss piece is equal to $1-s$. Reinvestment also implies the possibility to pay out part of the securitization proceeds to equity- or debtholders. Let the ratio of total payout to total assets be represented by $h$. Thus, the new proportion of funds to be reinvested is $s^{*} \equiv \frac{s-h}{1-h}$, while the proportion of the first loss piece in the new portfolio is $1-s^{*} \equiv \frac{1-s}{1-h}$. Accounting for possible payout to equity- or debtholders, the new ratio $s^{*}$ of reinvested funds. The new asset beta is then given by:

$$
\beta_{\text {assets }}^{\text {new }}=\left(1-s^{*}\right) \cdot \beta_{F L P}+s^{*} \cdot \beta^{\text {reinvest }} .
$$

By combining Eq. (5) and (6), we obtain a general formula for the relation between original and new bank equity beta after securitization ${ }^{5}$ :

$\Delta \beta_{\text {equity }}=\frac{\left(1-s^{*}\right) \cdot \beta_{F L P}+s^{*} \cdot \beta^{\text {reinvest }}}{e^{\text {new }}}-\frac{\beta_{\text {assets }}^{\text {orig }}}{e^{\text {orig }}}-\frac{\beta_{\text {debt }}^{\text {new }} \cdot d^{\text {new }}}{e^{\text {new }}}+\frac{\beta_{\text {debt }}^{\text {orig }} \cdot d^{\text {orig }}}{e^{\text {orig }}}$,

Thus, magnitude and direction of equity beta change depend on bank leverage before and after securitization as well as the beta of the reinvestment alternative chosen. Figure 5 shows in two panels the change in bank equity beta

\footnotetext{
${ }^{5}$ Note that payouts may have any effect on firm leverage, ranging from an increase to a decrease, depending on how the payouts are distributed between equity- and debtholders. Equally, firm leverage may also change without any payouts due to balance sheet restructurings.
} 
after a securitization transaction. The left diagram shows how equity beta changes in response to different leverage, given a constant beta of reinvested assets $\beta^{\text {reinvest }}=\beta_{\text {assets }}^{\text {orig }}$. The plot shows that, for constant leverage, for increasing leverage, and even for to some extent decreasing leverage, $\beta_{\text {equity }}^{\text {new }}$ is larger than $\beta_{\text {equity }}^{\text {orig }}$. The right diagram shows how equity beta changes in response to different beta of reinvested assets, given a constant equity ratio of 0.1 which is typical in the banking sector. The plot shows that equity beta rises in most cases and only decreases if the beta of reinvested assets is substantially below the beta of the original portfolio. Thus, we conclude that equity beta may rise or fall in response to a securitization transaction, but in most practically relevant cases, it will rise.

It is worth noting that there is a substantial difference between synthetic and true sale transactions with respect to the change in equity beta. The argument as outlined above, i.e. that beta may rise or fall in response to a securitization transaction, holds for true sale transactions. In the case of synthetic transactions, however, the argument changes: Since all claims are settled at maturity, there are no immediate cash flows from the transaction that can be reinvested in new securities or distributed to equity- or debt-holders. Consequently, in the case of synthetic transactions, there will always be a decrease in equity beta if there are no other offsetting transactions.

The analysis presented in this paper builds on a one-factor macroeconomic risk model. In extended versions with several independent risk factors, the results remain essentially unchanged. There are only more sensitivities and 
beta changes that have to be considered, each likewise represented by Eq. (7).

\section{Systemic Risk}

In the last section we have established that under certain conditions relating to the retention of first loss pieces, the securitization of a loan portfolios by a bank will lead to an increase in its exposure to market risk. We found the increase of the issuing institution's systematic risk to be positively related to the size of the retained equity piece, and to the reinvestment beta of the issue proceeds. Beta always decreases for synthetic issues, since there are no issue proceeds.

All these claims pertain to the individual bank. What do they imply for the banking sector as a whole? On the basis of the simple risk transfer model introduced in this paper, we now estimate the correlation of defaults. This corresponds to a widely used definition of systemic risk, the likelihood of a concurrent failure of several banks, see Kaufman (2000) or Lehar (2005). ${ }^{6}$ For any given joint loss rate distribution, one can determine the cumulative density of a certain number $n$ or more banks defaulting simultaneously. This will be our approach to capture system-wide default risks, and we will investigate the relationship between systematic risk exposure on the level of the individual bank and its contribution to the risk of multiple bank failures.

\footnotetext{
${ }^{6}$ Kaufman (2000) surveys the many different definitions of systemic risk used in the literature. These definitions have received considerable attention, probably because the containment of systemic risk is one of the core justifications for banking supervision, and for central bank interventions in financial markets.
} 


\subsection{How securitization affects joint default probabilities}

The previous section has concluded that the securitization of a bank's loan portfolio combined with the retention of a junior claim on the asset pool, tends to raise the bank's equity beta. Therefore one may ask: What is the marginal effect of such a beta rise on the likelihood of multiple bank failure? To answer this question we run a Monte Carlo simulation with many banks, all modeled as in section 4 . We let one bank securitize its loan portfolio, tranching the portfolio according to the rules outlined in section 3, selling all tranches except the most subordinate one, and reinvesting the proceeds in assets of a similar quality as the securitized loan portfolio ${ }^{7}$.

Table 8 shows, for a market consisting of 5 banks, the probability that a certain number of banks default. In the base case of no securitization, i.e. all banks holding on to their original loan portfolios, the probability of at least one bank defaulting amounts to $42.13 \%$ while the probability that all banks default amounts to $39.88 \%$. Thus, in the majority of all cases, either all banks or no bank will default. ${ }^{8}$

Table 8 compares the performance of banks and shows the probabilities of

\footnotetext{
${ }^{7}$ The assumption that new loans have similar characteristics as the old loans is for ease of exposition only. In section 4 , it was shown that the change in macro factor exposure has the predicted same sign as long as the reinvestment beta is not too much smaller than the beta of the original loan portfolio. So, for instance, the re-investment of ABS proceeds in riskless government bonds could actually lower the issuing banks equity beta. If this is the case, the effect on systemic risk is the other way around.

${ }^{8}$ Note that the number of bank defaults is dominated by the realization of the macro factor in this example. The dominance of macro factor realizations is due to (1) the large size of the loan portfolios with 10000 loans each and (2) the rather high correlation assumption of 0.3 between all loans. However, our calculations for more realistic average correlations show that the numbers do not change much. Still, realizations of the macro factor dominate the results, i.e. in the majority of all cases, either all banks or no bank default.
} 
at least $1,2, \ldots, 5$ banks defaulting simultaneously. The numbers reported are cumulative probabilities. The first column shows the base case, when no bank securitizes its loan portfolio. In this case, the probability of just one bank defaulting is $42,13 \%$, in line with the high individual default probability assumed in these simulations (see section 4 for details). Changing the individual default probabilities will downshift the numbers in column 1 as well. The second column reports the effect of one securitizing bank on the joint default probabilities of $1, \ldots, 5$ banks. There is a uniform increase in system-wide joint default probability for the different levels of joint default in Table 8. The third column assumes that all five banks engage in one round of asset securitization. The numbers in the table indicate that securitization increases the risk of joint bank defaults at each level, represented by the minimum number of banks jointly defaulting. While the probability that at least one bank defaults is $42.13 \%$ if all banks hold on to the original loan portfolio, the default probability increases to $56.05 \%$ if all banks sell off their loan portfolios, retaining the first-loss piece, and reinvest the proceeds in new loans. Similar increases can be observed for all other levels of systemic risk, i.e. that at least 2, 3, 4, or 5 banks default. Correspondingly, the probability of a joint default of all five banks rises by 14.15 percentage points in comparison to the base case of no securitization and reaches $54.03 \%$.

The results reported in Table 8 support the claim that asset securitization may increase the systematic risk exposure of these banks. Furthermore, the risk transfer by even a single financial institution will contribute to an increase of the systemic risk of the banking sector. Note that the source of systemic risk in 
our model is not contagion, or any other inter-bank liability, but the impact of a common macroeconomic factor in the return generating process ${ }^{9}$. The reason why securitization levers macroeconomic risk has been shown in this and the previous section: it is the influence that securitization (or structured funding in general) exerts on the systematic risk of the bank's asset composition. In our simulations, this influence is due to a) the retention of the most subordinate tranche, and b) to the characteristics of the reinvestment decision concerning the generated new funds.

Overall, these results show how the mechanics of tranching and securitization relate to systemic risk, providing a framework for more precise regulation.

\subsection{Inferring systemic risk from market betas}

In the previous section, we have shown that by the use of collateralized debt obligations, based on the mechanics of tranching and securitization, banks may increase their systematic risk, and thereby may raise the stability risk of the financial system at large. We have captured the bank's macro factor exposure by beta, the bank return's standardized covariance with the volatility of the market index. We now turn our approach on its head and analyze whether or not a change of a bank's equity beta is an indicator of an increased systemic banking risk. This question is important, since an affirmative answer would give us an easy-to-use instrument at hand that allows the monitoring of joint bank

\footnotetext{
${ }^{9}$ In the recent literature on systemic bank risk, there is an emphasis on inter-bank financial relationships as the main source of systemic risk, see De Bandt and Hartmann (2002) for a survey.
} 
default rates, or synonymously, systemic risk. On the other hand, the question is not trivial, because it is conceivable that a) securitizations lead to increased systematic and systemic risk, as shown in sections 4 and 5 , and b) both effects are actually a consequence of the bank retaining the highly risky first loss piece of the securitization. Thus, the increase in systemic risk reported earlier, may be due to the specific risk allocation achieved in structured finance, but it may not be caused by an increase in beta itself. To put it differently, in this section we will analyze whether an increase in beta will always increase the joint default probability of banks, independent of the reason for the shift in beta.

Table 8 reports the results of a Monte Carlo simulation with five banks, all of which have the same characteristics (equity ratio of $10 \%$, default probability of $10 \%$, and equal betas). However, in contrast to earlier simulations, we do not assume anything about securitization and reinvestment. Instead, we model the bank as a return generating entity with a given macro risk exposure, summarized by its beta value. We look at three distinct scenarios. In the first scenario, all banks have a zero macro factor exposure, i.e. each individual beta is equal to zero. Results are in col.1 of Table 8.

We find a rapid decay in the probability of joint bank defaults for higher numbers of banks involved. Thus, the probability of one bank or more failing is $40.55 \%$, while it is $7.96 \%$ for two or more and $0.05 \%$ for 4 or 5 banks failing jointly. If we increase beta uniformly to the level of 1 , the probabilities for more than one bank failure is rising for all levels of systemic crisis, relative to the base case in col.1. Only the probability of just one bank failure is reduced, 
indicating that probability mass is shifted from independent default occurrence to joint defaults. If beta is increased further, to the uniform level of 2 , we find even higher systemic risk, i.e., the likelihood of multiple bank failures rises at all levels. Here again, the probability of a single bank failure is reduced, due to increased macro factor dependence. Thus, a unanimous increase in equity beta for all banks leads to a higher probability of multiple bank defaults.

Summing up, we showed how bank equity betas relate to the probability of multiple bank defaults. In particular, we find support for the hypothesis that individual bank equity betas are an important statistic for multiple bank failure risk.

\section{Conclusion}

This paper traces the effect of a financial innovation on the risk profile of an individual bank, and more generally on the stability of the banking sector. The financial innovation we are looking at is the securitization of the loan book. Throughout the paper, we employ numerical methods, which allows us to closely examine the nature of risk transfer.

The key finding in this paper is a positive relationship between subordination and macro factor dependence. We find senior tranches to have a low correlation with the macro factor, while junior tranches have substantial positive correlation, far higher than the underlying asset portfolio itself. This result implies that under plausible conditions concerning the properties of the under- 
lying credit assets and the retention of the first loss piece, the systematic risk of the issuing bank, as measured by its equity beta, will rise. To derive this result we have projected the portfolio default rate of individual tranches on a macro risk factor, which in turn served to generate the returns of the individual loans, together with an idiosyncratic risk factor. We also show that the risk position of a bank that securitizes its loan portfolio and reinvests the proceeds differs substantially from commonly used credit loss distributions. Furthermore, we simulate the dependency between tranches of different transactions, but with the same risk rating. The correlation coefficients tend to be highest for the most senior tranches.

Our results show that the banking industry increases its dependence on the macro risk factor by securitizing its asset pool. From the point of view of a regulator, an increased macro risk dependence of individual banks also raises the probability of joint defaults. This, however, raises the likelihood of observing a banking crisis - many financial intermediaries failing at the same time. In our setting, the commonality is due to a high dependency of banks on general macroeconomic conditions, which implies that banks tend to suffer large loan losses at the same time.

Our simulations suggest that credit backed securitizations render banks more vulnerable against adverse movements of the macroeconomic factor. This conclusion is subject to the retention of the first loss piece, while mezzanine and senior tranches are sold to outside investors. A more aggressive risk acquisition by issuing banks would make our results even stronger, see Acharya (2001) and 
Instefjord (2005).

Note that the increased dependency of first loss banks (i.e. banks that keep securitizing their loan portfolio while retaining the first loss piece) on macro risks goes hand in hand with an effective transfer of extreme systematic risks. These latter risks are realized if several banks fail at the same time, and the severity of these losses is then borne by the holders of the senior tranches. The transfer of extreme systematic risk stabilizes the banking system, while the banks' systematic risk rise nevertheless.

Do the new rules known as Basel II solve the problem of systematic risk increase through an increase in minimum equity capital? Under Basel II regulation, the holder of an equity tranche has to hold $100 \%$ equity against this position. One can therefore conclude that as long as the minimum capital requirement is binding, an increase in asset beta through securitization will be balanced off by a lower debt ratio. However, empirically we observe a trend for banks in many countries, and in particular for internationally active banks, to increase their effective equity capital far above the minimum capital requirement (see Allen et al., 2005, for a survey and an explanation of this development), thereby rendering the above formulation invalid: when minimum capital requirement is not binding, then the issue of credit backed securities (retaining the junior tranche) will most likely increase bank equity beta.

Furthermore, as worked out in section 5, the increase of systematic bank equity risk in the wake of risk transfer through securitized loan assets affects the correlation among different financial institutions. The joint dependency is 
what beta is intended to capture after all. Therefore, we have concluded that securitization not only raises systematic bank risk, but it also raises systemic risk of the entire banking sector. There are three questionable assumptions that underlie our conclusion. First, why should the most subordinate tranche of a securitization transaction be retained? Second, are there any compensating effects in other segments of the financial system that offset the increase in systemic risk? Third, are beta values truly useful if one wants to forecast the stability of a financial system vis-à-vis exogenous macroeconomic shocks? We will deal with these questions in turn.

Equity piece retention is widely observed in the industry, according to survey evidence published by the Bundesbank (2004), and by the European Central Bank (2004). What is the economic function of the retention of first loss pieces? The question has been analyzed in the theoretical literature by Plantin (2004), and by DeMarzo (2005). These authors show that the retention of a first loss piece serves the purpose of a deductible in insurance markets, aligning the incentives of the issuing bank with the interests of the buyers of the senior tranches. Thus, first loss piece retention is all the more important, the stronger is the role of relationship lending in the pool of securitized assets. Arm's length lending, in contrast, is less likely to require any deductible in order to be sold on the market place. Thus, we expect our line of argument from securitization to systemic risk to be notably relevant for commercial banks with large midcap industry loans and private relationship lending.

The second question really describes an open research question. If securi- 
tizations in the banking sector raise average beta of the sector, there must be a compensating effect elsewhere in the economy, since average beta equals one by construction. The relevant question is therefore whether the offsetting effect happens within the financial system, or outside of the system. The latter case may be due to a decreasing beta of household assets, which were bank bonds before securitization, and are senior CDO tranches afterwards. There are clearly a great many possible compensating effects that need further study.

There may be additional reasons to believe that a bank that securitizes its liabilities will end up increasing asset risk. One powerful argument has been made by Acharya (2001), who endogenizes the choice of correlation risk by banks. Acharya (2001) shows that depending on the capital requirements imposed on banks, they may find it attractive to increase correlation risk, due to moral hazard. A good example is a pertinent bank regulation that focuses on the individual default risk of banks (Value at Risk, for example), neglecting correlation risk. In such a case, banks will become creative in order to raise the unpriced correlation risk. Of course, and as shown before, one way of achieving increased correlation risk is through securitizing assets. The current reform of banking regulation, Basel II, does not address the correlation risk, and therefore illustrates well the point raised by Acharya (2001).

What are the lessons for financial stability supervision? First, the effect of credit risk transfer on banks' systematic risk can be estimated using either numerical models, or using empirical data. In both cases regulators will want to hold average bank beta at level compatible with banks' capital reserves. 
Since non-proportional risk sharing is increasingly used not only in the banking industry, but also in corporate finance and in the reinsurance industry, we expect our analysis to have relevance even beyond the field of credit risk management. Overall, the analysis stresses the importance for both investors, banks, and regulators to better understand the risk allocation in securitization transactions.

\section{References}

[1] Acharya, V. (2001). Theoy of systemic risk and design od prudential bank regulation, working paper, London Business School.

[2] Allen, F., E. Carletti, and R. Marquez (2005). Credit market competition and capital regulation, working paper.

[3] Allen, F., D. Gale (2005). Systemic risk and regulation, NBER woking paper, forthcoming: The Risks of Financial Institutions, edited by M. Carey and R. Stulz, University of Chicago Press.

[4] Andersen, T., T. Bollerslev, F. Diebold, and P. Christoffersen (2004). Practical volatility and correlation modeling for financial market risk management, working paper, October.

[5] Deutsche Bundesbank (2004). Instrumente zum Kreditrisikotransfer: Einsatz bei deutschen Banken und Aspekte der Finanzstabilität, Monatsbericht April, 24-45. 
[6] Das, S.R., L. Freed, G. Geng, and N. Kapadia (2004). Correlated default risk, working paper, June.

[7] De Bandt, O., P. Hartmann (2002). Systemic risk: A survey, in Financial crisis, contagion and the lender of last resort: A book of readings, ed by C.A.E. Goodhart and G. Illing, Oxford University Press, London, 249-298.

[8] DeMarzo, P. (2005). The pooling and tranching of securities: a model of informed intermediation, Review of Financial Studies 18, 1-35.

[9] Duffie, D., N. Gârleanu (2001). Risk and valuation of collateralized debt obligations, Financial Ananlysts Journal 57, January-February, 41-59.

[10] European Central Bank (2004). Credit risk transfer by EU banks: activities, risks, and risk management. Report, May.

[11] Franke, G., J. P. Krahnen (2005). Default risk sharing between banks and markets: the contribution of collateralized debt obligations, NBER working paper, forthcoming: The Risks of Financial Institutions, edited by M. Carey and R. Stulz, University of Chicago Press.

[12] Gibson, M.S. (2004). Understanding the Risk of Synthetic CDOs, working paper.

[13] Greenbaum, S., A. Thakor (1987). Bank funding modes: securitization versus deposits, Journal of Banking and Finance 11, 379-392.

[14] Instefjord, N. (2005), Risk and hedging: do credit derivatves increase bank risk?, Journal of Banking and Finance 29, 333-345. 
[15] J.P. Morgan (2004). Global ABS/CDO Weekly Market Snapshot, Global Structured Finance Research, JP Morgan New York, June 10.

[16] Kaufman, G.G. (2000). Banking and currency crises and systemic risk: A taxonomy and review, Financial Markets, Institutions $\mathcal{E}$ Instruments, 9, 2, May.

[17] Lehar, A. (2005), Measuring systemic risk: A risk management approach, Journal of Banking and Finance 29, 2577-2603.

[18] Plantin, G. (2004). Tranching, working paper, London School of Economics.

[19] Rosenberg, J.V., T. Schuermann (2004). A general approach to integrated risk management with skewed, fat-tailed risks, Federal Bank of New York, staff report no. 185, May. 
Table 1: Summary statistics for tranches

This table presents summary statistics for the seven tranches, representing claims of strict subordination on the underlying portfolio. The statistics indicate the allocation of losses of the underlying portfolio to the individual tranches. The cut-off values for a particular tranche is determined by the default probability allowed for that tranche as indicated in the fifth column. The most junior tranche (tranche number 7) corresponds to the first loss piece. It bears all losses not covered by the other, more senior, tranches. The columns present, from left to right, the tranche number, the tranche size, mean loss, loss standard deviation, default probability, and loss given default. The last row displays the statistics for the underlying portfolio.

\begin{tabular}{|c|c|c|c|c|c|}
\hline Tranches & $\begin{array}{c}\text { Tranche } \\
\text { size }\end{array}$ & Mean loss & Loss std & $\begin{array}{c}\text { Default } \\
\text { probability }\end{array}$ & LGD \\
\hline 1 & $61.61 \%$ & $0.07 \%$ & $0.84 \%$ & $1.000 \%$ & $6.68 \%$ \\
\hline 2 & $3.70 \%$ & $1.48 \%$ & $11.35 \%$ & $2.000 \%$ & $73.92 \%$ \\
\hline 3 & $5.54 \%$ & $3.32 \%$ & $16.46 \%$ & $5.000 \%$ & $66.48 \%$ \\
\hline 4 & $5.14 \%$ & $7.23 \%$ & $24.25 \%$ & $10.000 \%$ & $72.30 \%$ \\
\hline 5 & $6.02 \%$ & $14.53 \%$ & $32.79 \%$ & $20.000 \%$ & $72.66 \%$ \\
\hline 6 & $3.93 \%$ & $24.69 \%$ & $41.15 \%$ & $30.000 \%$ & $82.29 \%$ \\
\hline 7 & $14.06 \%$ & $60.96 \%$ & $34.28 \%$ & $99.996 \%$ & $60.97 \%$ \\
\hline Total & $100.00 \%$ & $11.07 \%$ & $8.93 \%$ & $99.996 \%$ & $11.07 \%$ \\
\hline
\end{tabular}


Table 2: Bilateral correlations of tranches from two different CDO issues - base case

This table displays the bilateral correlations of all tranches from two different CDO issues ranging from tranche number 1 (most senior tranche) to tranche number 7 (first loss piece). Both CDOs have similar characteristics: The reference portfolio consists of 10'000 loans, and all of them have a default probability of $20 \%, 1$ year maturity, $47.5 \%$ recovery rate, and $6 \%$ coupon. All loans are assumed to have a default correlation of 0.3 . All cash flows are discounted with a constant interest rate of $4 \%$. The loss distribution is calculated with 50'000 simulations.

\begin{tabular}{|c|c|c|c|c|c|c|c|c|}
\hline & & \multicolumn{7}{|c|}{ CDO 2} \\
\hline & & Tranche 1 & Tranche 2 & Tranche 3 & Tranche 4 & Tranche 5 & Tranche 6 & Tranche 7 \\
\hline CDO 1 & $\begin{array}{l}\text { Tranche } 1 \\
\text { Tranche } 2 \\
\text { Tranche } 3 \\
\text { Tranche } 4 \\
\text { Tranche } 5 \\
\text { Tranche } 6 \\
\text { Tranche } 7\end{array}$ & 0.9977 & $\begin{array}{l}0.6896 \\
0.9964\end{array}$ & $\begin{array}{l}0.4672 \\
0.7638 \\
0.9972\end{array}$ & $\begin{array}{l}0.3044 \\
0.4977 \\
0.7718 \\
0.9976\end{array}$ & $\begin{array}{l}0.2074 \\
0.3392 \\
0.5260 \\
0.7764 \\
0.9982\end{array}$ & $\begin{array}{l}0.1458 \\
0.2385 \\
0.3698 \\
\\
0.5459 \\
0.8113 \\
0.9978\end{array}$ & $\begin{array}{l}0.0906 \\
0.1482 \\
0.2298 \\
0.3392 \\
0.5041 \\
0.6824 \\
0.9991\end{array}$ \\
\hline
\end{tabular}


Table 3: Bilateral correlations of tranches from two different CDO issues $\rho=0.15$

This table displays the bilateral correlations of all tranches from two different CDO issues ranging from tranche number 1 (most senior tranche) to tranche number 7 (first loss piece). Both CDOs have similar characteristics: The reference portfolio consists of 10'000 loans, and all of them have a default probability of $20 \%, 1$ year maturity, $47.5 \%$ recovery rate, and $6 \%$ coupon. All loans are assumed to have a default correlation of 0.15 . All cash flows are discounted with a constant interest rate of $4 \%$. The loss distribution is calculated with $50^{\prime} 000$ simulations.

\begin{tabular}{|c|c|c|c|c|c|c|c|c|}
\hline & & \multicolumn{7}{|c|}{ CDO 2} \\
\hline & & Tranche 1 & Tranche 2 & Tranche 3 & Tranche 4 & Tranche 5 & Tranche 6 & Tranche 7 \\
\hline CDO 1 & $\begin{array}{l}\text { Tranche } 1 \\
\text { Tranche } 2 \\
\text { Tranche } 3 \\
\text { Tranche 4 } \\
\text { Tranche } 5 \\
\text { Tranche 6 } \\
\text { Tranche } 7\end{array}$ & 0.9965 & $\begin{array}{l}0.6619 \\
0.9918\end{array}$ & $\begin{array}{l}0.4495 \\
0.7617 \\
0.9934\end{array}$ & $\begin{array}{l}0.2922 \\
0.4953 \\
0.7681 \\
0.9943\end{array}$ & $\begin{array}{l}0.1990 \\
0.3374 \\
0.5233 \\
0.7759 \\
0.9955\end{array}$ & $\begin{array}{l}0.1395 \\
0.2365 \\
0.3669 \\
0.5441 \\
0.8112 \\
0.9946\end{array}$ & $\begin{array}{l}0.0818 \\
0.1387 \\
0.2151 \\
0.3190 \\
0.4757 \\
0.6438 \\
0.9982\end{array}$ \\
\hline
\end{tabular}


Table 4: Bilateral correlations of tranches from two different CDO issues - 100 loans

This table displays the bilateral correlations of all tranches from two different CDO issues ranging from tranche number 1 (most senior tranche) to tranche number 7 (first loss piece). Both CDOs have similar characteristics: The reference portfolio consists of 100 loans, and all of them have a default probability of $20 \%, 1$ year maturity, 47.5\% recovery rate, and $6 \%$ coupon. All loans are assumed to have a default correlation of 0.3 . All cash flows are discounted with a constant interest rate of $4 \%$. The loss distribution is calculated with 50'000 simulations.

\begin{tabular}{|c|c|c|c|c|c|c|c|c|}
\hline & & \multicolumn{7}{|c|}{ CDO 2} \\
\hline & & Tranche 1 & Tranche 2 & Tranche 3 & Tranche 4 & Tranche 5 & Tranche 6 & Tranche 7 \\
\hline CDO 1 & $\begin{array}{l}\text { Tranche } 1 \\
\text { Tranche } 2 \\
\text { Tranche } 3 \\
\text { Tranche 4 } \\
\text { Tranche } 5 \\
\text { Tranche 6 } \\
\text { Tranche } 7\end{array}$ & 0.8145 & $\begin{array}{l}0.6308 \\
0.7792\end{array}$ & $\begin{array}{l}0.4635 \\
0.7166 \\
0.8441\end{array}$ & $\begin{array}{l}0.3000 \\
0.4990 \\
0.7269 \\
0.8532\end{array}$ & $\begin{array}{l}0.2028 \\
0.3387 \\
0.5194 \\
0.7420 \\
0.8808\end{array}$ & $\begin{array}{l}0.1431 \\
0.2389 \\
0.3682 \\
0.5444 \\
0.7727 \\
0.8636\end{array}$ & $\begin{array}{l}0.0894 \\
0.1493 \\
0.2300 \\
0.3407 \\
0.5051 \\
0.6662 \\
0.9246\end{array}$ \\
\hline
\end{tabular}


Table 5: The effect of systematic risk on tranches

This table presents the effect of systematic risk on tranches. All loans are assumed to have a default correlation of 0.3 , a default probability of $20 \%, 1$ year maturity, $47.5 \%$ recovery rate, and $6 \%$ coupon. All cash flows are discounted with a constant interest rate of $4 \%$. The calculations are performed with 50'000 simulation runs. The first column shows the tranches considered, ranging from 1 (most senior tranche) to 7 (first loss piece). The second column reports the unconditional default rates of the tranches. The third column reports the default rate of each tranche conditional on the default of a bond only subject to macroeconomic risk. The fourth column specifies the probability of a macro bond default, given the default of a particular tranche.

\begin{tabular}{lccc}
\hline Tranche & $\mathrm{P}^{\mathrm{d}}($ tranche) & $\mathrm{P}^{\mathrm{d}}$ (tranche $\mid$ macro) & $\mathrm{P}^{\mathrm{d}}$ (macro $\mid$ tranche) \\
\hline 1 & $1.00 \%$ & $4.95 \%$ & $100.00 \%$ \\
2 & $2.00 \%$ & $9.92 \%$ & $100.00 \%$ \\
3 & $5.00 \%$ & $24.80 \%$ & $100.00 \%$ \\
4 & $10.00 \%$ & $49.61 \%$ & $100.00 \%$ \\
6 & $20.00 \%$ & $98.42 \%$ & $99.22 \%$ \\
7 & $30.00 \%$ & $100.00 \%$ & $67.21 \%$ \\
\hline Total portfolio & $100.00 \%$ & $100.00 \%$ & $20.15 \%$ \\
\hline
\end{tabular}


Table 6: Tranche beta

This table presents the results from a regression relating tranche returns to the corresponding realizations of the macroeconomic factor. All loans are assumed to have a default correlation of 0.3 , a default probability of $20 \%, 1$ year maturity, $47.5 \%$ recovery rate, and $6 \%$ coupon. All cash flows are discounted with a constant interest rate of $4 \%$. The calculations are performed with 50 '000 simulation runs. The first column shows the tranches considered, ranging from 1 (most senior tranche) to 7 (first loss piece). Columns two to four report beta values of the regression $r=\alpha+\beta \cdot Y_{M}+\epsilon$ for the base case as well as alternative cases with 100 loans and a correlation of 0.15 , respectively.

\begin{tabular}{lccc}
\hline & \multicolumn{3}{c}{ Estimated $\beta$} \\
\cline { 2 - 4 } Tranche & Base case & 100 loans & Corr $=0.15$ \\
\hline 1 & 0.0020 & 0.0016 & 0.0014 \\
2 & 0.0374 & 0.0363 & 0.0369 \\
3 & 0.0734 & 0.0722 & 0.0725 \\
4 & 0.1364 & 0.1341 & 0.1358 \\
5 & 0.2258 & 0.2217 & 0.2259 \\
6 & 0.3137 & 0.3070 & 0.3139 \\
7 & 0.3200 & 0.3175 & 0.2596 \\
\hline Total portfolio & 0.0846 & 0.0847 & 0.0598 \\
\hline
\end{tabular}


Table 7: The effect of portfolio diversification

This table presents, for three correlation scenarios, the standard deviation of losses for different numbers of loans. The numbers in parentheses indicate the reduction factor of the standard deviation obtained when increasing the number of loans in the portfolio by the factor 10 . In the three correlation scenarios, all loans are assumed to have a default correlation of $0.0,0.15$, and 0.3 , respectively. All loans have a default probability of $20 \%, 1$ year to maturity, $47.5 \%$ recovery rate, and $6 \%$ coupon. All cash flows are discounted with a constant interest rate of $4 \%$. The calculations for the different portfolios are performed with 50'000 simulation runs each.

\begin{tabular}{cccc}
\hline \multirow{2}{*}{ Number of loans } & \multicolumn{3}{c}{ Standard deviation } \\
\cline { 2 - 4 } & Corr=0.0 & Corr=0.15 & Corr=0.30 \\
\cline { 2 - 4 } 1 & $22.13 \%$ & $22.19 \%$ & $22.20 \%$ \\
\multirow{2}{*}{10} & $7.04 \%$ & $9.12 \%$ & $11.01 \%$ \\
& $(3.146)$ & $(2.432)$ & $(2.017)$ \\
100 & $2.21 \%$ & $6.52 \%$ & $9.19 \%$ \\
& $(3.178)$ & $(1.399)$ & $(1.198)$ \\
1000 & $0.70 \%$ & $6.21 \%$ & $8.98 \%$ \\
& $(3.167)$ & $(1.051)$ & $(1.023)$ \\
10000 & $0.22 \%$ & $6.16 \%$ & $8.95 \%$ \\
& $(3.163)$ & $(1.007)$ & $(1.004)$ \\
\hline
\end{tabular}

Table 8: Multiple bank defaults

This table shows the probability of multiple bank defaults. The examined market consists of 5 banks holding loan portfolios from different obligors, but with otherwise identical characteristics. The given numbers are probabilities that at least a certain number of banks in the market default. The default probabilities are given for three scenarios: (1) no bank securitizes, i.e. all banks hold on to their original loan portfolios, (2) one bank securitizes its loan portfolio, retaining the first-loss piece and reinvesting the proceeds, and (3) all banks securitize their loan portfolios.

\begin{tabular}{lccc}
\hline $\begin{array}{l}\text { Minimum number } \\
\text { of bank defaults }\end{array}$ & $\begin{array}{c}\text { No bank } \\
\text { securitizes }\end{array}$ & $\begin{array}{c}\text { One bank } \\
\text { securitizes }\end{array}$ & $\begin{array}{c}\text { All banks } \\
\text { securitize }\end{array}$ \\
\hline 1 & $42.13 \%$ & $55.04 \%$ & $56.05 \%$ \\
2 & $41.47 \%$ & $42.01 \%$ & $55.46 \%$ \\
3 & $40.98 \%$ & $41.27 \%$ & $55.05 \%$ \\
4 & $40.49 \%$ & $40.69 \%$ & $54.60 \%$ \\
5 & $39.88 \%$ & $40.00 \%$ & $54.03 \%$ \\
\hline
\end{tabular}


Table 9: Systemic risk and beta

This table shows the probability of multiple bank defaults. The examined market consists of 5 banks holding loan portfolios from different obligors, but with otherwise identical characteristics. The given numbers are probabilities that at least a certain number of banks in the market default. The default probabilities are given for three scenarios with different bank equity betas. The tuples in the first row indicate the equity-beta values of each of the 5 banks in the market.

\begin{tabular}{lccc}
\hline $\begin{array}{l}\text { Minimum number } \\
\text { of bank defaults }\end{array}$ & $(0,0,0,0,0)$ & $(1,1,1,1,1)$ & $(2,2,2,2,2)$ \\
\hline 1 & $40.55 \%$ & $39.76 \%$ & $38.55 \%$ \\
2 & $7.96 \%$ & $8.78 \%$ & $9.49 \%$ \\
3 & $0.84 \%$ & $1.20 \%$ & $1.58 \%$ \\
4 & $0.05 \%$ & $0.10 \%$ & $0.17 \%$ \\
5 & $0.00 \%$ & $0.01 \%$ & $0.01 \%$ \\
\hline
\end{tabular}


Figure 1: Loss distribution of a loan portfolio

This diagram presents the loss distribution of a loan portfolio at maturity. The underlying portfolio consists of 10'000 securities from different obligors. All securities have the same characteristics: identical exposure size, $6 \%$ coupon 1 year to maturity, $20 \%$ default probability, $47.5 \%$ recovery rate, and identical exposure to the macro factor $\left(\rho_{n, M}=0.3\right)$. All cash flows are discounted with a constant interest rate of $4 \%$. The evolution of individual-loan credit quality over time is simulated at annual frequency. The calculations are performed with 50'000 simulation runs. The horizontal axis shows the loss rate; the vertical axis shows the observed frequency.

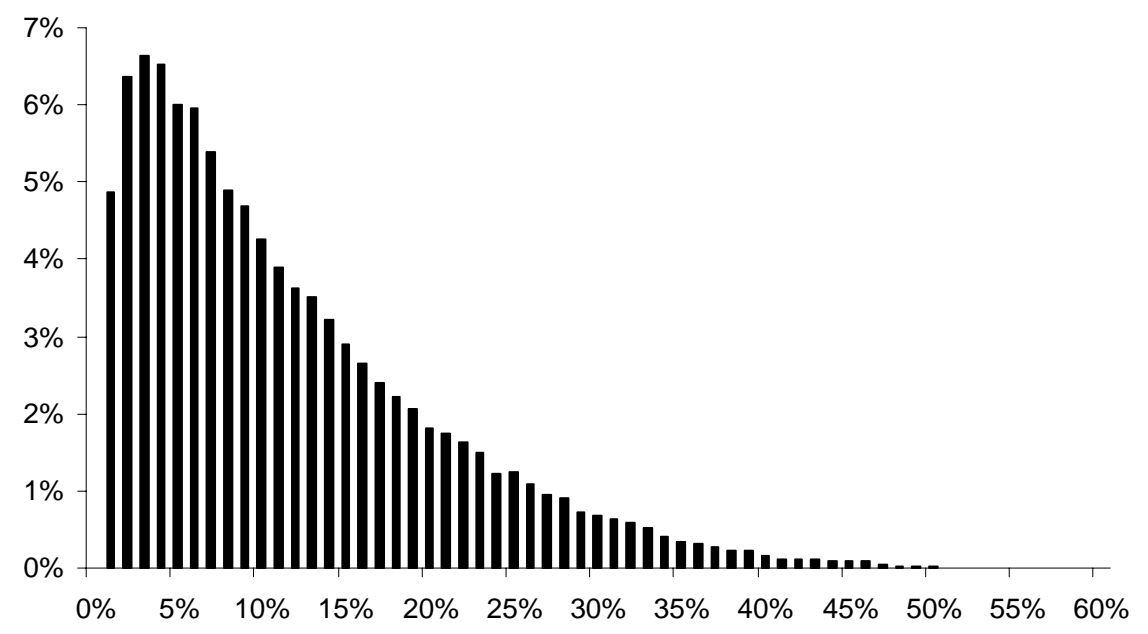


Figure 2: Loss distribution of tranches

This diagram presents the loss distribution of three tranches (from left to right): the first loss piece (tranche 7), a mezzanine tranche (tranche 6), and the senior tranche (tranche 1). The calculations are performed with 50'000 simulation runs. The horizontal axis shows the loss rate; the vertical axis shows the observed frequency, truncated at $30 \%, 1 \%$, and $0.2 \%$, respectively. There are several values surpassing these thresholds: For the first loss piece, $100 \%$ loss occurs at a frequency of $30 \%$. For the mezzanine tranche, zero loss occurs at a frequency of $70 \%$, and $100 \%$ loss occurs at a frequency of $20 \%$. For the senior tranche, zero loss occurs at a frequency of $99 \%$.
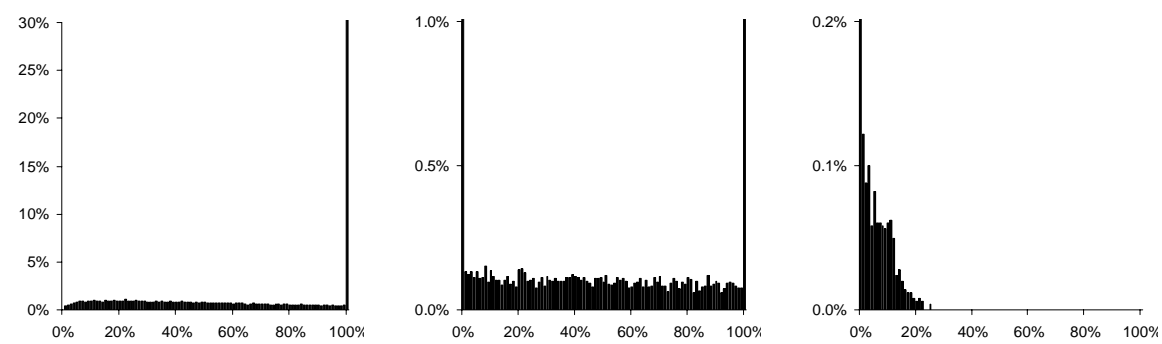

Figure 3: Tranche sensitivity to macro factor

This figure shows the sensitivity of individual tranches to realizations of the macro factor. The tranche numbers range from 1 (senior tranche) to 7 (equity piece). The vertical axis shows the loss rate with respect to the reference portfolio. The vertical axis shows the quantiles of macro factor realizations. High quantiles indicate good states of the economy.

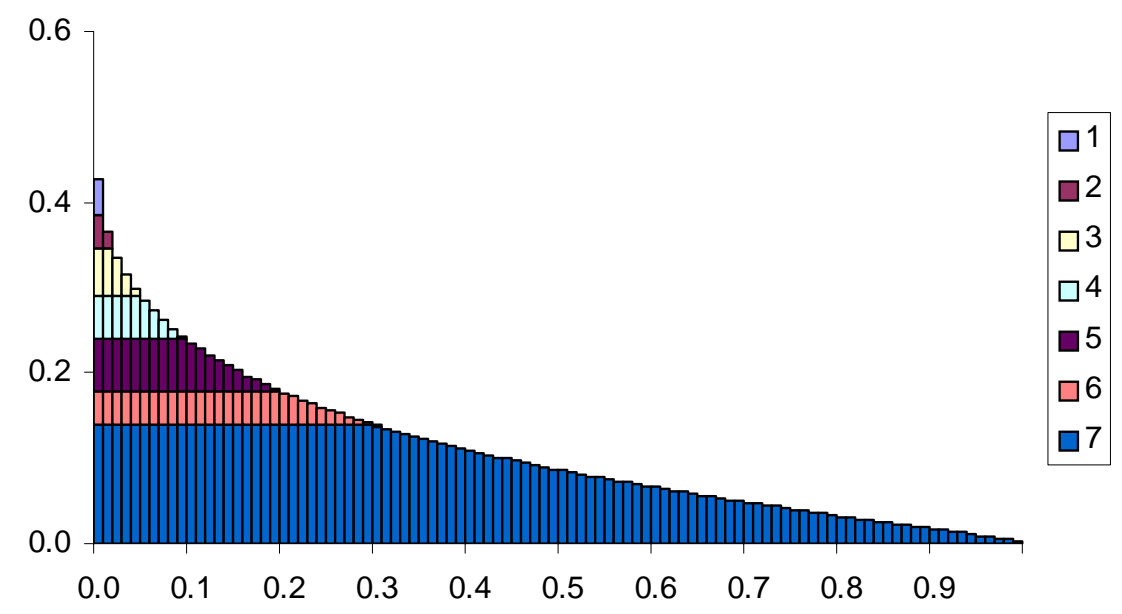


Figure 4: Loss distribution of a loan portfolio after repeated securitizations and reinvestments

This figure shows the loss distribution of a loan portfolio after repeated securitizations and reinvestments. The original portfolio is securitized by retaining a first loss piece of 14.06 percent. The proceeds obtained from the securitized portion (85.94 percent of the initial portfolio) amount to 94.26 percent of the total portfolio value as obtained with a one-factor asset pricing model. This amount is reinvested in a new portfolio consisting of identical loans. Loss distributions are shown for several iterations ranging from zero (the original portfolio is kept) to infinity (the limit case). The horizontal axis shows the loss incurred with respect to the initial portfolio value, determined with a one-factor asset pricing model. Negative values indicate excess returns. The vertical axis shows the frequency of relative losses.

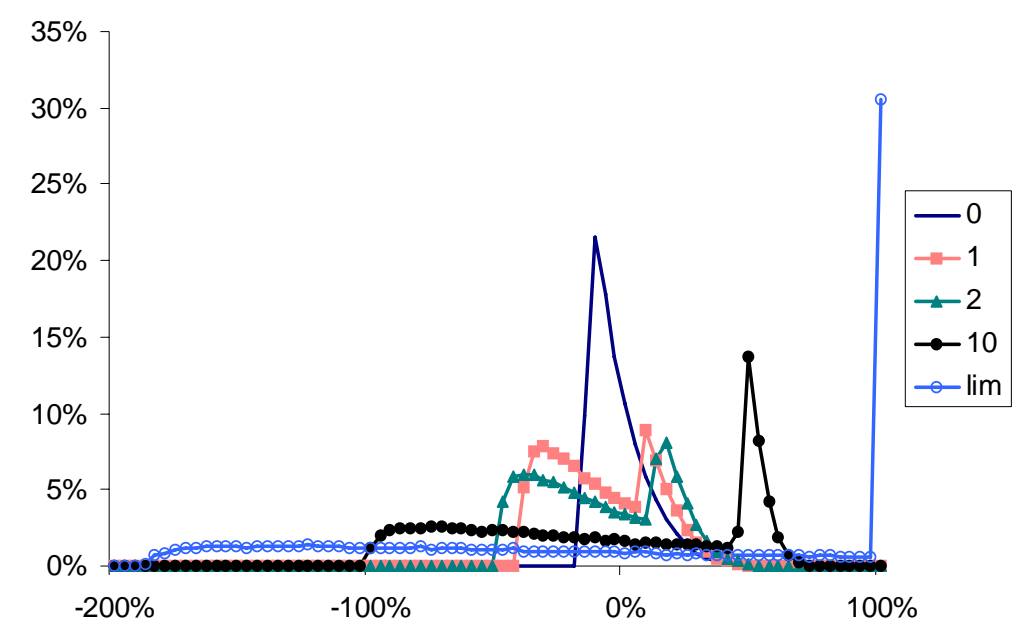


Figure 5: Bank equity beta change after securitization

This figure shows change of bank equity beta after securitization for various values of firm leverage (panel a) and beta of reinvested assets (panel b). The beta of debt is set to zero. The first loss piece has a share of 14.06 percent of the total portfolio. The beta of the original portfolio as well as the reinvested securities is 0.0846 , the beta of the first loss piece is 0.3200 , the original and the new equity ratios are 0.1 , corresponding to typical values for banks. In panel a, the new equity ratio is varied (vertical axis), in panel $b$, the beta of the reinvested securities is varied (x-axis). In panel a, there is a positive (negative) change in equity beta for equity ratios smaller (larger) than 0.139. In panel $\mathrm{b}$, there is a positive (negative) change in equity beta for a weighted average beta of reinvested securities larger (smaller) than 0.046. Leaving both firm leverage and portfolio beta of reinvested securities constant, the resultung equity beta change of the bank is 0.3310 .

Panel (a)

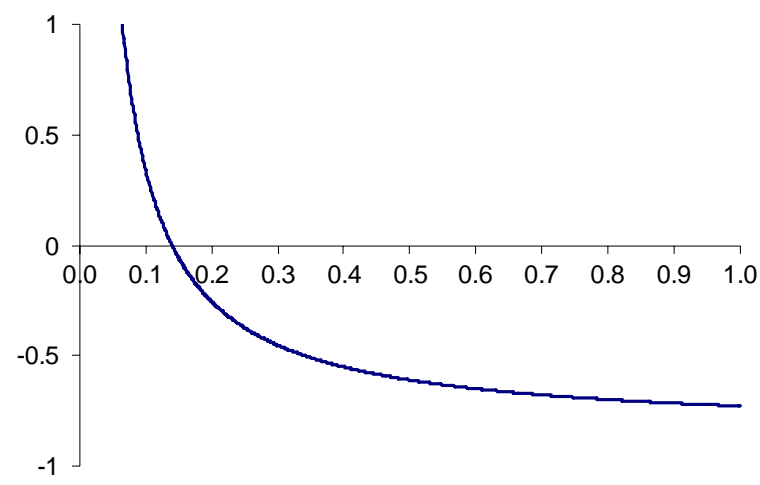

Panel (b)

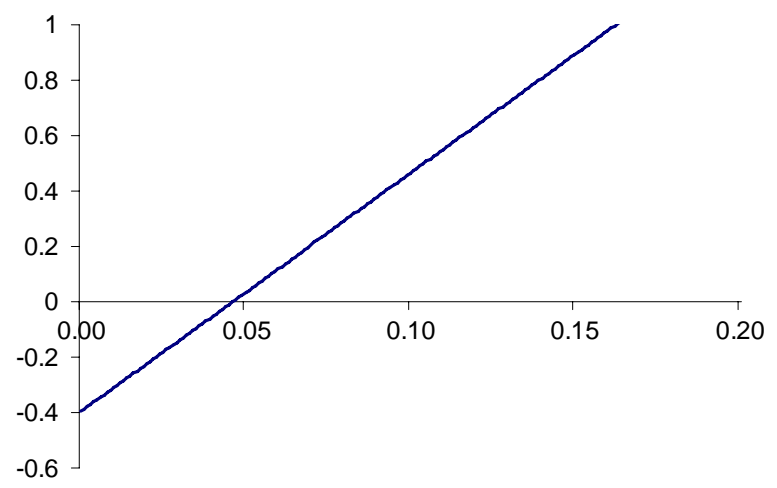

